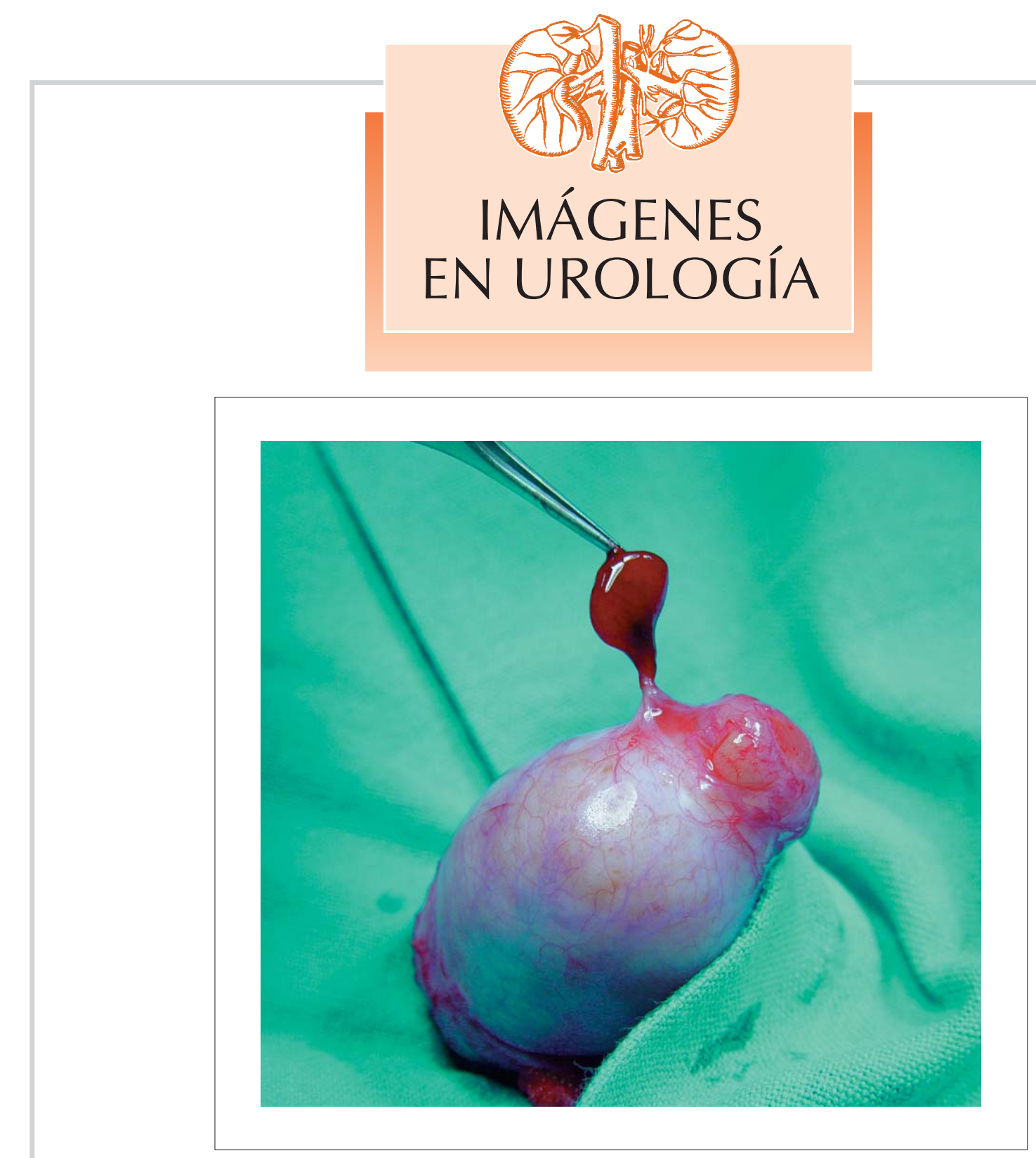

\title{
ESCROTO AGUDO: TORSIÓN DE HIDÁTIDE TESTICULAR SÉSIL DE MORGAGNI
}

Los anejos testiculares, estructuras vestigiales embrionarias, aparecen en el $80-90 \%$ de los testículos. Están formados por tejido fibroso recubriendo un eje vascular. Por un mecanismo de rotación se puede producir un estrangulamiento del pediculo vascular, produciendo una torsión del anejo de tipo hemorrágico o trombótico dando lugar a un cuadro de "escroto agudo". La clinica es más moderada que en la torsión testicular aguda, con dolor menos intenso y con menos afectación del estado general. A la exploración puede palparse o transiluminarse un nódulo azulado en polo superior del testículo, denominado "signo de la gota azul" y presente en el 25 $30 \%$ de los casos. El tratamiento habitual en caso de absoluta certeza del diagnóstico es la analgesia y los anti-inflamatorios. Si la clinica no cede, como en el caso que presentamos, o existen dudas diagnósticas debe realizarse una exploración quirúrgica escrotal bajo anestesia con resección del anejo torsionado. En la imagen de nuestro caso puede observarse la torsión hemorrágica de un apéndice testicular sésil de Morgagni con el testículo normal. Fue resecado el apéndice y la evolución del paciente fue favorable.

E. Fernández Rosado, A. Blanco Díez, A. Barbagelata López, L. Álvarez Castelo, S. Novas Castro, M. González Martín. Servicio de Urología. Complejo Hospitalario Universitario Juan Canalejo. La Coruña. 